\title{
DATVP Regimen
}

National Cancer Institute

\section{Source}

National Cancer Institute. DATVP Regimen. NCI Thesaurus. Code C9578.

A chemotherapy regimen consisting of daunorubicin, cytarabine, thioguanine, vincristine, and prednisone that may be used in the treatment of acute lymphoblastic leukemia (ALL). 